\title{
Charles Boxer (contra Gilberto Freyre): raça e racismo no Império Português ou a erudição histórica contra o regime salazarista ${ }^{1}$
}

\section{Charles Boxer (against Gilberto Freyre): race and racism in the Portuguese Empire or historical erudition against Salazar's regime Alberto Luiz Schneider}

Em 1963, o historiador britânico Charles Boxer(1904-2000) - então professor da Cátedra Camões, do King's College London - publicou um livro que causou furor no Brasil e, sobretudo, em Portugal. Trata-se de Race relations in the Portuguese Colonial Empire, 1415-1825. A obra era fruto de três conferências proferidas na Universidade da Virgínia, nos Estados Unidos, em novembro de 1962: "Morocco and West Africa", "Moçambique and India" e "Brazil and Mara-

\footnotetext{
Alberto Luiz Schneider é doutor em História pela Unicamp, com pós-doutorado no King's College London e no Departamento de História da USP. É professor de História da PUC-SP, São Paulo, Brasil (alberto.ls@uol.com.br).

Este artigo é parte do pós-doutorado na USP, financiado pela FAPESP.

Artigo recebido em 30 de junho e aprovado para publicação em 10 de setembro de 2013.
}

Est. Hist., Rio de Faneiro, vol. 26, no 52, p. 253-273, julho-dezembro de 2013. 


\section{Alberto Luiz Schneider}

nhão". Nesses ensaios, Boxer, um historiador moderado, empirista, distante das teses marxistas em voga na época - e bem relacionado nos círculos intelectuais portugueses - denunciava com rigor histórico e erudição as práticas raciais no Império Português da Era Moderna.

Já nas primeiras páginas do livro, o autor citava uma entrevista concedida pelo primeiro-ministro de Portugal, António de Oliveira Salazar, à revista britânica Life, na qual este afirmava que os contatos entre os colonizadores portugueses e os povos colonizados "jamais envolveram a menor ideia de superioridade racial ou discriminação" (Boxer, 1967: 35). ${ }^{2}$ Autor de livros importantes como The Christian century in Fapan, 1549-1650 (1951), Salvador de Sá and the struggle for Brazil and Angola, 1602-1686 (1952) e The Dutch in Brazil (1957) -, Boxer introduziu assim em sua agenda intelectual um tema que até então não havia despertado atenção de modo mais sistemático: a questão racial na história da expansão lusitana ao longo da Era Moderna. Ao abordar diferentes regióes, tempos e contextos do império, o historiador britânico buscou evidenciar uma regularidade, embora diferente na intensidade em função da região e da época: a violência e a discriminação dos portugueses em relação aos povos colonizados, a despeito da miscigenação e da convivência que a colonização impôs. O livro provocou a fúria de Salazar, o que implicou a interdição em Portugal da obra de Boxer, somente reeditada após a Revolução dos Cravos (1974). Além disso, Race relations foi alvo de ferozes ataques na imprensa portuguesa e brasileira de homens de letras e prestígio (próximos do regime português), como Armando Cortesão e Gilberto Freyre.

Hoje soa profundamente banal a afirmação de que a longa experiência imperial e escravocrata dos portugueses na Ásia, na África e na América tenha gerado práticas racistas. Em 1963, essa afirmação - atualmente incorporada aos enquadramentos mentais em vigor - precisava ser demonstrada, tal era a força da tese segundo a qual o "mundo que o português criou" era substancialmente diferente da prática habitual do racismo colonial, tida como própria dos ingleses ou dos holandeses. As teses luso-tropicalistas - que animaram a produção intelectual de Gilberto Freyre na década de 1950, início da de 1960 - serviram ao regime salazarista para converter cinco séculos de colonização em "cinco séculos de relações entre povos e culturas diferentes"; uma sociedade colonial, em "plurirracial"; uma nação imperial, em "pluricontinental", e as colônias, em "províncias ultramarinas" (Ribeiro, 2004).

Race relations é incompreensível sem pensarmos no chão histórico do início dos anos 1960, no contexto das guerras de descolonização e da apropriação que o regime de Salazar faria do luso-tropicalismo usinado por Gilberto Freyre. O autor pernambucano atribuía a Portugal um papel histórico, o de "confraternizar lírica e franciscanamente com os povos dos trópicos"(Freyre, 1953a: 99). O 
discurso luso-tropical de Freyre - nos anos 1950 e princípio dos anos 1960 - foi apropriado seletivamente pelo Estado Novo português, especialmente após a revogação do Acto Colonial, com a revisão constitucional de 1951, em que se acentuou um "unitarismo uniformizador", coroado pela ideia da constituição de um Estado português pluricontinental, do Minho ao Timor, numa mística luso-cristã de assimilação (Léonard, 1999: 42). ${ }^{3}$

Nos anos 1950 - com Um brasileiro em terras portuguesas (1953a), Aventura e rotina (1953b) e Integração portuguesa nos trópicos (1958) -, Freyre formulou a ideia de uma "civilização luso-tropical", definida como o resultado da interpenetração dinâmica entre a matriz cultural portuguesa e as condições ecológicas, culturais, materiais e étnicas da vida nos trópicos. Essa formulação, cada vez menos antropológica e sociológica, e mais ideológica, alcançou seu ápice em O luso e o trópico (1961), publicado no âmbito da comemoração do V Centenário da Morte do Infante D. Henrique, realizada em Lisboa em 1960. Aliás, é altamente significativo que Freyre tenha proferido a conferência inaugural do Congresso Internacional de História dos Descobrimentos, intitulada "Integração das raças autóctones na economia portuguesa".

No prefácio de O luso e o trópico, Freyre afirmava que os escritos serviam para comemorar o início da aventura lusitana, outrora esposada pelo Infante D. Henrique, figura que "concorreu decisivamente para dar às relações de europeus com não europeus, de brancos com povos de cor, um rumo peculiarmente luso-cristão". No texto, Freyre não deixava de referir-se à "atualidade" da questão racial, numa conjuntura internacional em que se tornava "necessário e essencial ao mundo que se reorganiz[asse] o encontro, sob a forma de um encontro entre iguais do Ocidente com o Oriente [...], através da miscigenação e da interpenetração de culturas" (Freyre, 1961: 3). Estaria em curso a formação de um "terceiro homem" ou de uma "terceira cultura", a luso-tropical, uma civilização que não tinha sido considerada na tipologia de Toynbee (Castelo, 1999).

Freyre partia da premissa de que as colônias portuguesas na África eram Brasis na infância. Por essa razão, em sua viagem à África portuguesa, a convite do regime, o autor se decepcionou em Cabo Verde, "predominantemente africana na cor, no aspecto e nos costumes" (Freyre, 1953a: 266), mas a produção literária da região o consolou, pois nela encontrou "a mais viva literatura luso-tropical, depois da do Brasil" (Idem: 280). Em Angola, sentiu-se mais confortável com a população assimilada de Luanda, que se percebia portuguesa, segundo afirmou. O futebol angolano lembrava a ginga brasileira. Freyre estava mais interessado em compreender a atuação dos portugueses nos trópicos do que em entender o modo de vida dos africanos em face da experiência colonial portuguesa. É expressivo notar que as teses luso-tropicais são antes brasilocêntricas do que $l u$ socêntricas: "Sinto-me aqui numa espécie de Alto Amazonas ou de Alto Mato 


\section{Alberto Luiz Schneider}

Grosso Português, que sendo já antigo território lusitano, só agora começasse a realmente aportuguesar-se" (Idem: 281). Adriano Moreira, então ministro do Ultramar, conhecedor da obra de Gilberto Freyre e entusiasta do luso-tropicalismo, em discurso proferido em 1961 insistiu na ideia de que a África sob o domínio português era uma espécie de laboratório de um futuro desejável, formado por pequenos Brasis: "Queremos [...] uma política cujos benefícios estão documentados pelo maior país do futuro que é o Brasil" (Moreira apud Almeida, 2000: 177).

A celebração da vida e dos feitos de D. Henrique (1394-1460) foi cuidadosamente elaborada em 1960 - num momento em que o regime português se encontrava sob forte tensão política, inclusive por parte da ONU e da opinião pública internacional - a fim de exaltar os empreendimentos do primeiro (e último) império europeu na África. Teve a participação de inúmeros intelectuais, artistas e políticos, com particular destaque para Freyre e para o então presidente do Brasil, Juscelino Kubitschek de Oliveira, bem como de todo o establishment português, incluindo Oliveira Salazar, evidentemente. Além da parada naval, da edificação de monumentos e da confecção de medalhas e selos comemorativos, foi organizado - na Universidade de Lisboa - um encontro com 800 pesquisadores, provenientes de 85 países. O evento tinha a função de relembrar ao mundo a antiguidade e a legitimidade do mais antigo império europeu, então em perigo. Todo o investimento político e simbólico que o regime estabeleceu em torno das comemorações henriquinas - assim como na apropriação das teses luso-tropicais de Freyre - atendia a uma lógica cristalina: convencer o mundo (e a própria sociedade portuguesa) acerca da excepcionalidade das relações coloniais na África, marcadas pela miscigenação e pela integração.

Boxer participou do V Centenário de Morte do Infante D. Henrique e presenciou a natureza francamente política do evento. $\mathrm{O}$ historiador discursou em nome dos representantes britânicos no congresso, citando evento similar em Londres, no British Museum (1960), intitulado Prince Henry the Navigator and the Portuguese Maritime Enterprise (Catalogue of an Exhibition at the British Museum, 1960), financiado justamente pela Comissão Executiva das Comemorações daquele V Centenário (Garcia, 2005: 185). ${ }^{4}$

No princípio da década de 1960, Portugal foi objeto de duríssimas críticas de intelectuais estrangeiros, como os norte-americanos Basil Davidson e James Duffy, que contestaram a política lusa de repressão e discriminação dos nativos em Angola, Guiné-Bissau e Moçambique. James Duffy, autor de Portugal in Africa (1963), foi um dos pioneiros no estudo sistemático da história da África nos Estados Unidos. No entanto, a crítica mais dolorosa e deletéria aos interesses portugueses partiu de José Honório Rodrigues, autor de Brasile África: outro horizonte (1961). O historiador brasileiro - coincidentemente amigo de Boxer 
(Souza, 2010) - criticou severamente a política externa brasileira, acusando-a de subserviente tanto aos interesses dos Estados Unidos quanto aos interesses de Portugal (Thomaz, 2002; Maxwell, 2006; Guimarães, 2009).

O ano de 1961 representou importante abalo na secular presença lusitana na África. Rebeldes angolanos iniciaram uma série de articulações e ataques armados contra as instalações coloniais. Em Guiné-Bissau, eclodiu um violento movimento cujo objetivo declarado era expulsar os portugueses da região. Naquele ano, o Conselho de Segurança da ONU - com o endosso formal e o apoio político dos Estados Unidos - expediu uma resolução condenando a repressão contra a população local. Em dezembro de 1961, o exército da Índia invadiu e ocupou Goa, colocando um ponto final em cinco séculos de presença portuguesa em território indiano, embora o regime de Salazar jamais o reconhecesse. Em Moçambique, durante o ano de 1962, eclodiu um movimento organizado cujo objetivo expresso era a libertação da região sob o secular domínio português. Aliados históricos de Portugal, como a Inglaterra, recusaram-se a socorrer o país, diplomática ou militarmente.

Os anos de 1961 e 1962 foram marcados pela agitação política em torno das ideias de "raça" e de racismo, temas que rapidamente ganharam espaço nas ciências sociais, na historiografia e nos estudos literários. Precisamente nesse contexto, Race relations in the Portuguese Colonial Empire foi escrito, originalmente destinado ao público universitário norte-americano, de modo geral partidário da descolonização e dos direitos civis. Charles Boxer realizou uma "operação historiográfica" (Certeau, 1982) destinada a evidenciar as práticas racistas dos portugueses no ultramar - entre os séculos XV e XIX na Ásia, na África e na América -, conferindo centralidade ao Brasil, em clara resposta ao repertório luso-tropicalista. $\mathrm{O}$ historiador demonstrou que as relações raciais no Império Português absolutamente não representaram o quadro de integração que Gilberto Freyre - durante os anos 1950 - fez supor, e menos ainda a propaganda oficial do regime salazarista. Através da utilização de extensa massa documental, Boxer apresentou uma visão complexa e heterogênea das relações raciais nos territórios de colonização lusa, distante dos discursos sedutores em voga no Brasil e em Portugal.

É interessante notar que uma intervenção propriamente historiográfica, como a de Boxer, articulou temporalidades diversas, em que o historiador - situando-se no presente e refletindo o presente - pôde olhar para o passado e indagá-lo sob outra ótica. Afetada pelas expectativas e disputas do presente, a intervenção historiográfica de Boxer contribuiu para alterar a leitura do passado, no mesmo momento em que o presente (os anos 1960, aqueles personagens, inclusive o historiador que não pode viver fora do tempo) vivia uma fissura que ameaçava ruir, como viriam a ruir o regime de Salazar e o colonialismo, bem como o 


\section{Alberto Luiz Schneider}

prestígio e a força de Gilberto Freyre, cada vez mais questionado, especialmente pelo pensamento marxista que se enraizava na universidade brasileira. Hoje, o argumento de Race relations parece profundamente corriqueiro, mas quando o livro foi publicado, em 1963, representou uma tensão historiográfica de grandes proporções, capaz de mobilizar os intelectuais da época - tensão que advinha menos do tempo narrado (a Era Moderna) e mais do tempo do narrador (os anos 1960). Nesse contexto, pode-se compreender a crítica do livro aos "escritores portugueses modernos", pois, quando estes afirmam

[que] seus compatriotas jamais tiveram qualquer preconceito racial ou discriminação contra o negro africano, evidentemente ignoram que uma raça não pode escravizar outra por mais de três séculos, sistematicamente, sem adquirir um sentimento, consciente ou não, de superioridade racial (Boxer, 1967: 91).

A expressão “escritores portugueses" certamente incluía Armando Cortesão, que em 1962 publicou Realidades e desvarios africanos, livro em que defendia a presença portuguesa na África, qualificando-a como "fundamentalmente diferente" da empresa de outros colonizadores europeus, uma vez que os portugueses dos primeiros séculos estariam interessados em "cristianizar" e "civilizar" os nativos. Cortesão defendia Portugal da "maledicência" da crítica estrangeira, opondo-se às independências de Angola, Moçambique e Guiné, por considerá-las "prematuras", uma "das maiores calamidades de nosso tempo".

\section{A erudição contra o regime}

A obra Race relations arrola grande número de cronistas dos séculos XVI ao XVIII, sempre no sentido de evidenciar a postura "racista" dos portugueses. Apesar de mencionar textos críticos à escravidão - como o do padre Fernão de Oliveira (1507-1581) -, toda a argumentação de Boxer visa demonstrar o empenho escravocrata dos portugueses e de seus descendentes. O historiador cita desde as justificativas para a preação indígena do temido "bandeirante" Domingos Jorge Velho, em fins do século XVII, até a argumentação letrada desenvolvida em 1724 por Paulo Pereira Nunes, espécie de representante dos interesses dos colonos em Lisboa. Pereira Nunes havia vivido no "Grão-Pará e Maranhão" e defendido o trabalho forçado dos índios, valendo-se de referências eruditas como Platão, Virgílio e Plínio, além do jesuíta espanhol Juan Lorzano y Pereira e autoridades bíblicas. Chegou mesmo a discutir a origem dos índios, se estes des- 
cendiam de judeus deportados pelos assírios no tempo do rei Hosea ou se descendiam diretamente de Caim (Boxer, 1967: 131).

Ao tratar das relações raciais no Império Português da Era Moderna, o historiador inglês questionou, explicitamente, a justificativa ideológica do colonialismo português na África e, claro, a historiografia simpática ao regime. Embora não contestasse abertamente a interpretação de Freyre, Boxer conhecia sua obra e armou uma argumentação flagrantemente antigilbertiana: "Do que vimos espero que tenha ficado suficientemente claro que existia preconceito e tensão racial no Brasil colonial em grau muito maior que algumas autoridades sem citar nomes ou fazer alusões - admitem" (Idem). Entre as “autoridades" no assunto, ninguém no começo da década de 1960 era tão reputado quanto Gilberto Freyre. Boxer esmerou-se em historicizar a questão, evitando considerar de modo especial os portugueses mais racistas - eventualmente, menos - que outros colonizadores europeus:

Os portugueses não eram anjos nem diabos; eram seres humanos e agiam como tais; sua conduta variava muito de acordo com o tempo, lugar e espaço. Os plantadores brasileiros que surravam seus escravos até a morte por ofensas triviais eram quase que invariavelmente generosos e benévolos anfitrióes, e podiam ser capazes de afeição sincera por um negro ou mulato individualmente (Idem: 154-155).

Em Race relations, Charles Boxer evitou abrir uma explícita disputa interpretativa com Freyre, um intelectual sofisticado que se aproximou do salazarismo através do luso-tropicalismo, embora não possa ser confundido com a rasteira propaganda colonialista do regime (João, 2002: 663-670). Ainda que efetivamente debatesse com Freyre, Boxer preferiu escolher como inimigo o próprio "Dr. Salazar". De fato, era mais fácil enfrentar um ditador cada vez mais questionado do que um intelectual do porte de Freyre, cuja reputação era ainda fabulosa, embora já declinante. Para demonstrar que "a verdade é mais complexa", Boxer citou António de Oliveira Codornega (1624-1690), autor de História geral das guerras angolanas (1681-1683), na qual o cronista relata a execução em massa de chefes africanos acusados de conspirar contra o domínio português em 1624, acrescentando que o exemplo "tornou-se inesquecível para as gerações futuras, e deixou todos os pagãos destes reinos amedrontados e temerosos, pois apenas pela força e pelo medo que podemos manter nossa posição sobre estes indomáveis pagãos” (Boxer, 1967: 60). De maneira irônica, concluiu que o capitão Oliveira Codornega, que viveu mais de 40 anos na Angola do século XVII, era um guia mais autorizado que o "Dr. Oliveira Salazar". 


\section{Alberto Luiz Schneider}

A escravidão e o tráfico negreiro já haviam sido apresentados em livros como Salvador de Sá (1952) e The golden age of Brazil (1962), mas a questão propriamente racial não aparecia em tintas mais coloridas nessas obras de Boxer. Dauril Alden, biógrafo do historiador, afirma que ele "did not become concerned about the theory and practice of racial policy in the Portuguese empire until mid-1950" (Alden, 2001: 393). O que pode ter disparado seu interesse pelo tema foi a publicação, em 1949, do livro de seu amigo Lewis Hanke, The struggle for justice in the Spanish Empire. Boxer já tangenciara a questão em "Portuguese colonial slavery", artigo de 1954, mas não discutira a questão racial como o fez na década de 1960. Em 1961, Boxer afirmou sobre a África do Sul: "The oft-made claim the Portuguese had no colour-bar cannot be substantiated" (Boxer, 1961b). Naquele ano, o historiador proferiu uma conferência na British Academy, intitulada "The colour question in the Portuguese Empire, 1415-1825", mais tarde publicada sob o mesmo título. No texto, citava Edgar Prestage, seu antecessor na Cátedra Camões do King's College, além de vários outros estudiosos que haviam afirmado que os portugueses não teriam preconceitos, exceto com escravos e judeus. Freyre partilhava dessa perspectiva. Se as primeiras considerações não suscitaram maiores incômodos, Race relations gerou colérica reação em Portugal, embora tivesse positiva acolhida nos Estados Unidos, como sugerem as resenhas do livro (Alden, 2001: 374)

\section{Cortesão contesta Boxer}

Quando Race relations foi publicado pela Oxford University Press (Clarendon), em 1963, Charles Boxer contava 59 anos e já era o mais renomado historiador de língua inglesa dedicado ao Império Português, com uma longa lista de publicações. O autor do importante Portugaliae Monumenta Cartographica - juntamente com Alfredo Pinheiro Marques e Avelino Teixeira da Mota -, Armando Cortesão (1891-1977), que havia sido nominalmente citado por Boxer, era a pessoa certa para contestá-lo. Entre 27 de dezembro de 1963 e 4 de janeiro de 1964, o Diário Popular - prestigioso jornal português - publicou o primeiro de uma série de quatro textos, sob o título "O insidioso livro". Cortesão, o autor do texto, apresentava-se como um patriota que estaria sob ataque - bem como seu país -, afirmando que Boxer, antes um admirador do Império Português, teria se juntado aos seus inimigos. Enquanto se apresentava como um lusófilo, teria furtivamente recolhido documentos para atacar a história lusitana de modo "vil e enganoso". Cortesão apresentava Boxer como "oportunista e vira-casaca", citando passagens elogiosas da obra do historiador ao Império Português, para concluir que o intelectual britânico, além de estar errado, era um traidor por ter acusado os portugueses de serem racistas ao longo da sua história. 
Alguns intelectuais portugueses e brasileiros se solidarizaram com Boxer, entre eles Joel Serrão e José Honório Rodrigues. Em Pernambuco, José Antônio Gonsalves de Mello evitou tomar partido de forma explícita, mas não aderiu aos argumentos de Boxer. Em artigo de 1988, no Diário de Pernambuco, muitos anos depois das refregas da década de 1960, Gonsalves de Mello claramente defendeu Freyre:

O que Gilberto Freyre afirmou não é que não haja entre portugueses e brasileiros preconceito de raça sob nenhuma forma, mas que esse preconceito foi sempre, e continua a ser, mínimo, quando comparado com as formas como se apresentava entre povos europeus e da América do Norte (Mello, 1988).

Foi em São Paulo - onde a obra de Freyre era fortemente contestada pela chamada escola sociológica, liderada por Florestan Fernandes - que Boxer obteve espaço junto a Eurípedes Simões de Paula, editor da Revista de História da Universidade de São Paulo, para defender-se das acusações de Cortesão. Foi no primeiro semestre de 1964. Na nota intitulada "Resposta a artigos de Armando Cortesão", Boxer reafirmou sua tese, de que os portugueses do século XVI ao XVIII "nem sempre trataram os indígenas de África, Ásia e América 'humanamente, e quando civilizados, de igual para igual"'. Negou ainda que tenha feito alarde de erudição e afirmou ter tido o cuidado de selecionar trechos "bem típicos, e que, portanto, refletiam a prática e a mentalidade duma dada época ou região" (Boxer, 1964: 405-406).

No Brasil, Gilberto Freyre também reagiu contra Race relations, como não poderia deixar de ser. De acordo com Dauril Alden, Boxer e Freyre haviam se encontrado pela primeira vez em 1949 e, depois disso, em diversas outras ocasiões, inclusive em 1956, quando Freyre esteve na casa de Boxer - como ele próprio registrou em artigo na revista O Cruzeiro, intitulado "O professor Boxer", de 29 de dezembro de 1956. O livro de Freyre O luso e o trópico, de 1961, é dedicado a Américo Castro, Roger Caillois e Charles Boxer. Mas diante de Race relations, Freyre, que havia se transformado em loquaz defensor do Império Português, escreveu duas apreciações negativas: a primeira em "O nada estranho caso do Major Boxer", também publicado na revista O Cruzeiro de 6 junho de 1964, e depois em "Mais sobre o caso do Major Boxer", no Diário de S. Paulo de 29 de janeiro de 1965. No primeiro artigo, Freyre menosprezou Boxer, afirmando: "Ele não é Toynbee, nem um Trevelyan, nem mesmo um segundo Aubrey Bell ou outro Edgar Prestage [...] mas tem seu mérito". Menosprezo que parece não concordar com a dedicatória de poucos anos antes. A pior acusação, porém, foi a de que Bo- 


\section{Alberto Luiz Schneider}

xer não estava a serviço da história, e sim do combalido Império Britânico. Na segunda crítica, Freyre afirmou que o livro de Boxer daria munição aos movimentos de independência na África portuguesa, afirmação que era essencialmente correta e, ao que parece, não desagradaria a Boxer, ainda que o texto de Freyre tivesse a intenção de criticá-lo.

A África definitivamente estava na ordem do dia e gerava diferentes posições políticas, cada vez mais radicalizadas e polarizadas. As considerações de Freyre eram similares às de Armando Cortesão, que certamente conhecia os argumentos do sociólogo brasileiro. Aliás, Cortesão foi um dos organizadores do $\mathrm{V}$ Centenário de Morte do Infante D. Henrique e publicou Oluso e o trópico (1961), veemente defesa do colonialismo português.

\section{Uma leitura antigilbertiana}

A publicação de The Portuguese seaborne Empire, 1415-1825, em 1969, foi acompanhada de um texto introdutório escrito pelo historiador John Harold Plumb (1911-2001), professor do Christ's College da Universidade de Cambridge, renomado especialista da história britânica do século XVIII, que influenciou historiadores do peso de John Elliott, Quentin Skinner e Simon Schama, entre outros (McKendrick, 2001). No texto em que Plumb apresenta o livro de Charles Boxer, há apenas um único autor referenciado: o "grande historiador brasileiro Gilberto Freyre", identificado como alguém que "ajudou a consolidar" a tese da suposta inexistência do racismo no âmbito do Império Português. Plumb destaca o modo como Boxer - mediante a utilização de "maciça e conclusiva" documentação - desfaz a "lenda" que Freyre havia ajudado a erigir. Boxer evidentemente anuiu com o texto que prefaciava seu livro, deixando explícito o enfrentamento com Freyre, o que estava perfeitamente delineado em Race relations, ainda que de modo implícito.

Em um dos capítulos do livro de 1969, significativamente intitulado "Pureza de sangue e raças infectas", Boxer tornou a explorar a questão, vinculando a perseguição aos judeus, cristãos-novos e mouros à construção de um paradigma racial muito particular. As tensões étnico-culturais no Império Português do Antigo Regime - argumentava Boxer - assumiram um papel central nas instituições portuguesas, explícitas nos estatutos de pureza de sangue e nas habilitações para cargos, nas Ordens Militares, na hierarquia da Igreja ou mesmo nas Câmaras e Misericórdias, assunto que viria a ser explorado por Russel-Wood, um herdeiro de Boxer. ${ }^{5}$ A percepção continuou vigorosamente antigilbertiana, como se constata já no prólogo do livro, quando o historiador britânico finalmente assumiu a interlocução com "o famoso sociólogo brasileiro Gilberto Frey- 
re e seus discípulos", para quem - afirmava Boxer referindo-se ao argumento de Freyre - "a mulher moura, morena, também era vista como tipo invejável de beleza e de atrativo sexual, como comprovaria a duradoura popularidade das histórias da Moura torta". Boxer, ao selecionar essa passagem, pareceu discordar da explicação culturalista de Freyre, como sugere a sequência do trecho: "Daí à tolerância da mestiçagem racial, alegam esses sociólogos, só faltava um passo. Estava assim explicada a tendência dos portugueses -e, em menor grau, dos espanhóis de não praticar a segregação racial” (Boxer, 2002: 16). ${ }^{6}$

Boxer refletiu sobre as hierarquias sociais que orientavam privilégios e impedimentos, bloqueando a mobilidade social em função da cor e da herança étnica, aos quais se somavam outros - como aqueles que dificultavam a ascensão social de oficiais mecânicos, inclusive comerciantes que não fossem de grosso trato. A exclusão que originalmente se abatia sobre judeus e judaizantes, mouros e mouriscos - ou apenas cristãos-novos -, a partir do século XVI recaiu também sobre negros e mulatos que passaram a ser legal e especificamente discriminados. "No geral, os negros e os cripto-judeus suportavam o peso do preconceito e da perseguição raciais no mundo português" (Idem: 275). A abordagem de Boxer, mais empirista e institucional, partia de premissas muito diferentes das de Freyre, mais ensaísta e antropológica, num debate ora implícito, ora explícito, mas conscientemente contrário às teses de "autoridades contemporâneas eminentes", em alusão ao próprio Freyre, "que nos asseguram que os portugueses nunca tiveram preconceito racial digno de nota":

O que essas autoridades não explicam é por que, nesse caso, os portugueses, durante séculos, deram tanta ênfase ao conceito de "limpeza" ou "pureza de sangue", não só de uma classe, mas também de uma perspectiva racial, nem o motivo por que se encontram com tanta frequência expressões como "raças infectas" em documentos oficiais e na correspondência privada até o último quartel do século XVIII (Idem: 262).

Em sua obra, Boxer demonstrou que as pessoas de "sangue infecto" ou com "defeito de sangue", mesmo quando livres e até proprietárias, tinham suas possibilidades de ascensão constrangidas ou restritas, pois "o padrão social que prevalece era aquele da consciência da superioridade branca" (Boxer, 1967: 40). Para demonstrar sua tese, o historiador se debruçou sobre os obstáculos à formação de um clero multirracial no Brasil, na África ou na Ásia. As Constituições Sinodais do Arcebispado da Bahia, redigidas em 1707 e publicadas em 1719-20, ba- 


\section{Alberto Luiz Schneider}

seavam-se na jurisprudência portuguesa da época e referiam-se à "pureza de sangue do candidato", cuja comprovação passava por inquérito judicial

Em casos em que se provava a existência de algum "feito de sangue" ancestral podia-se obter a dispensa do bispo local ou da Coroa, como acontecia também em relação a outros imperativos judiciais, tais como nascimento ilegítimo e deformidade física. Na prática, isso acontecia com frequência; mas não se podia ter certeza prévia de que a dispensa seria obtida, e não era raro o inquérito judicial ser tão somente uma farsa. [...] Todas as ordens religiosas que se estabeleceram no Brasil mantiveram uma postura rígida de discriminação racial, contrária à admissão de mulatos (Boxer, 2002: 273).

Boxer insistiu nas nuances e contradições, como aquelas em que pessoas de "raças infectas" - como cristãos-novos e mulatos - conseguiam burlar o estatuto de "pureza de sangue". De fato, casos assim eram bastante comuns (Xavier, 2011). Mas, ao mesmo tempo em que mostrou a porosidade das regras do Antigo Regime, explicitou o quanto instituições e mentalidade pesavam contra as pessoas que portavam "defeitos de sangue". A Igreja foi uma das dimensões do Império mais estudadas por Boxer, em livros importantes como The Church militant and Iberian expansion, 1440-1770, de 1978. Boxer explorou a intensa rivalidade e preconceito de cor, no seio do clero secular, entre frades crioulos e seus confrades de origem europeia do clero regular.

[...] Por volta de 1720, tornara-se tão intensa na província franciscana do Rio de Janeiro que deu origem à promulgação de um breve papal decretando que todos os cargos deviam ser ocupados, alternadamente, por crioulos e indivíduos de origem europeia [...]. A ordem que mantinha a exigência racial mais rígida era a dos carmelitas descalços de Santa Tereza, que se fixou em Olinda em 1686. No decorrer dos 195 anos seguintes, esses frades se recusaram terminantemente a admitir noviços nascidos no Brasil, por mais "puro" que fosse o sangue deles, e recrutavam seus membros somente entre indivíduos nascidos na Europa e educados em Portugal, sobretudo na região do Porto (Boxer, 2002: 273-74).

Além da ação da Igreja, Boxer enfatizou o papel racialmente discricionário das instituições portuguesas, como as Câmaras e as Misericórdias. Em Portu- 
guese society in the tropics: the Municipal Councils of Goa, Macao, Bahia, and Luanda, 1510-1800 (1965), o autor já havia estudado em profundidade a questão. O tema reapareceu em The Portuguese seaborne Empire, sua grande obra de síntese, no capítulo intitulado "Conselheiros municipais e irmãos de caridade". No texto, Boxer demonstrou que, para participar da Santa Casa de Misericórdia - instituição que funcionava como uma instância nobilitante, de reconhecida relevância numa sociedade carente por títulos e distinção, como no Brasil colonial ou Goa - era necessário seguir critérios originalmente estabelecidos pela Misericórdia de Lisboa: "A versão do compromisso de 1618, que foi aceita pela maioria das irmandades coloniais com poucas modificações”. Assim, a qualificação exigida para participar de instituições tão caras ao Antigo Regime ibérico foi de alta significância:

1 - Comprovar pureza de sangue, sem nenhuma mancha de origem mourisca ou judaica, tanto no que dizia respeito ao irmão como à sua mulher, caso fosse homem casado.

2 - Não ter má reputação nas palavras, nas ações e na lei.

3 - Ser de idade adulta conveniente e ter mais de 25 anos completos, no caso de homem solteiro.

4- Não ser suspeito de estar servindo à Misericórdia em troca de pagamento.

5 - No caso de artesão ou comerciante, ser o mestre ou o dono do comércio, o responsável pela supervisão do trabalho de outros, em vez de executá-lo com as próprias mãos.

6 - Ser inteligente e alfabetizado.

7 - Ter situação suficientemente confortável para impedir qualquer tentação de desviar fundos da Misericórdia, e servi-la sem que isso lhe causasse nenhum embaraço financeiro (Boxer, 2002: 300).

Nos critérios da Misericórdia de Lisboa não foram mencionados negros, mulatos, índios ou brâmanes, por razões óbvias (embora houvesse negros e mulatos, escravos e livres em Portugal no século XVI). Mas as "nações" de cor certamente comprometiam a pureza de sangue do súdito. Se em Portugal o peso do estigma recaía, sobretudo, sobre os cristãos-novos, na América ou na Asia portuguesa a repulsa recaía sobre os mestiços da terra, mesmo quando livres e proprietários. Havia muitas irmandades no mundo português, inclusive de negros, e nem todas se orientavam por critérios raciais. Muitas delas - especialmente as 


\section{Alberto Luiz Schneider}

dominadas por brancos de extratos mais elevados - orientavam-se pelo espírito dos estatutos de "pureza de sangue".

Os estatutos da Ordem Terceira de São Francisco, de Mariana, em Minas Gerais, estipulavam, em 1763, que qualquer indivíduo que se candidatasse à admissão deveria ser "branco e legítimo de nascimento, sem nenhum boato ou insinuação de sangue judeu, mouro ou mulato, ou de carijó ou qualquer outra raça contaminada, o mesmo caberá à sua mulher, se for casado". [...] Os membros que viessem a se casar com uma moça de cor, ou de sangue cristão-novo, eram expulsos sem nenhuma cerimônia (Idem:306).

Referindo-se especificamente ao Brasil, de longe o maior mercado de escravos no Novo Mundo, Boxer relacionou a escravidão ao estigma do sangue que pesava de modo muito particular contra os negros e os mulatos, mostrando-se perplexo com os "escritores portugueses e brasileiros modernos", que haviam negado ou minimizado a existência de discriminação racial contra os negros. Não há qualquer dúvida que entre tais "escritores" estivesse Freyre, evidentemente.

A teoria aristotélica da inferioridade natural de algumas raças, com o corolário de que essas podiam ser legalmente escravizadas, foi enxertada, no Antigo Testamento, na história da maldição de servidão perpétua rogada por Noé à descendência de Canaã, filho de Ham (Gênesis IX, 25), de quem se pensava que os negros descendiam. Outras autoridades afirmavam que eles descendiam de Caim, "que havia sido amaldiçoado pelo próprio Deus". Teólogos e leigos estavam convencidos de que a Sagrada Escritura autorizava a escravidão negra, embora alguns censurassem, por motivos humanitários, o tratamento cruel infligido aos escravos. Além dessa justificação bíblica para a escravidão negra, escritores portugueses e brasileiros modernos, que alegam que seus antepassados jamais nutriam preconceito ou discriminação racial em relação aos negros africanos, ignoram inexplicavelmente o fato evidente de que uma raça não pode, de forma sistemática, escravizar os membros de outra, em larga escala, por mais de trezentos anos, sem adquirir, ao longo desse processo, um sentimento consciente ou inconsciente de superioridade racial (Idem: 276). 
O debate intelectual proposto por Charles Boxer - no tocante às questões raciais no Império Português - assumiu de aberto o enfrentamento: "deve-se enfatizar que a ascensão social do negro, que Gilberto Freyre afirma ter sido encorajada no Brasil, foi, ao contrário, propositalmente retardada nessa colônia, onde se manteve o preconceito racial rígido" (Boxer, 2002: 294). A partir de Race relations - e dos livros que vieram a seguir -, as premissas contidas no luso-tropicalismo estavam severamente avariadas, inclusive no âmbito da religião e da tradição evangelizadora - o que Freyre chamava de "colonização cristocêntrica". Porém é importante notar que a agenda intelectual de Boxer era diferente da agenda de Freyre. O historiador britânico, grande conhecedor dos cronistas da Era Moderna, enfocou aspectos institucionais, mentais e ideológicos dos agentes históricos, em geral letrados portugueses que atuavam no Império e nas colônias, enquanto Freyre, permeado por uma perspectiva antropológica, priorizou o cotidiano e a sociabilidade, a sexualidade e as afetividades, o que explica parte dessa diferença. O próprio conceito de "raça" e o sentido de sua apreensão são distintos nos dois autores. Freyre é herdeiro das agendas intelectuais da primeira metade do século XIX, onde o estigma biologizante da raça ainda era mote de intenso debate. A sombra da inferioridade de um Brasil mestiço - herdado do racismo científico do XIX - atormentava Freyre, empenhado em mostrar antropologicamente a positividade de um Brasil ibérico e miscigenado (Vainfas, 1999: 8). Boxer, embora fosse apenas quatro anos mais jovem que Freyre, é intelectualmente um homem do pós-guerra (até porque sua carreira intelectual começou tardiamente). Estrangeiro, não estava preocupado nem com o "atraso", nem com a "inferioridade", mas, sim, interessado em compreender as "raças infectas" no âmbito dos estigmas e das hierarquias do Antigo Regime português - em que o sangue, a linhagem e a ancestralidade eram fundamentais.

Boxer não desconsiderou o papel da miscigenação tão cara a Freyre, mas enfatizou a natureza desigual e violenta desse processo, muitas vezes impulsionada pela simples ausência de mulheres brancas nos espaços coloniais. Ao relativizar a tese gilbertiana da propensão lusa à miscibilidade, Boxer deduziu que a experiência brasileira foi singular, fruto das circunstâncias e das possibilidadesregionalmente diversa -, e não de uma essência cultural miscigenante dos portugueses nos trópicos.

Os textos de Boxer da década de 1940 eram, certamente, muito diferentes da sua produção dos anos 1960. Não é sem sentido a consideração de Cortesão de que o historiador teria sido um "vira-casaca". O que mudou afinal? É preciso lembrar que o contexto internacional do pós-guerra ${ }^{7}$ catapultou a questão racial para o centro do debate político e social, o que seguramente influenciou sua percepção. Quando Boxer proferiu as conferências na Virgínia, em novembro de 1962, a consciência acerca das guerras africanas - como a sangrenta Guerra de 


\section{Alberto Luiz Schneider}

Angola, iniciada em 1961 - povoava suas inquietações, que eram também as de amplos segmentos da época. $O$ fato de o historiador conhecer o Império Português, inclusive o turbulento passado de Angola e do tráfico de escravos - objeto de estudo em Salvador de Sá and the struggle for Brazil and Angola, 1602-1686-, colocou-o em condições privilegiadas para refletir a questão.

Após sua aposentadoria no King's College London, Charles Boxer se mudou, em 1967, para Bloomington, nos Estados Unidos. Entre 1969 e 1972, foi professor da Universidade de Yale, da cadeira intitulada Expansion of Europe Overseas (Alden, 2001: 454). Outro dado biográfico importante é o fato de Boxer ter sido casado com a escritora norte-americana Emily Hahn (1905-1997), mulher de tendências feministas e progressistas, que havia morado na África e na China. Essa conexão com os Estados Unidos foi decisiva para que Boxer optasse, nos anos 1960 e 1970, por refletir sobre as práticas racistas dos portugueses ao longo da história moderna. Como nota João de Pina Cabral, Boxer se colocou ao lado do seu tempo. Vale afirmar, se colocou ao lado de Martin Luther King, dos nacionalistas e anticolonialistas africanos, e dos jovens universitários.

These were, therefore, the lectures that he delivered to his students in the American campuses at Yale, Virginia and Bloomington precisely during those mutinous years. After all, he was to move from Bloomington to Yale the year after Martin Luther King, Fr. was killed. There was no way he could have lived there and avoided the issue (Cabral, 2012).

A partir da década de 1960, Boxer contribuiu para a formação de uma nova consciência histórica acerca das relações raciais no "mundo que o português criou", na qual a questão racial se tornou central para quem estudava os Impérios modernos. As formulações de Gilberto Freyre já não cabiam em tal leitura (nem era esse o Freyre que a historiografia da década de 1990 recuperaria; autor cuja fecundidade resiste à caducidade ideológica de parte de sua obra).

A obra de Boxer voltaria a circular na historiografia portuguesa pós-Revolução dos Cravos (1974) e a partir da década de 1990 foi crescentemente revalorizada no Brasil. Não há espaço aqui - nem é intenção deste artigo - para avaliar a repercussão de Boxer na historiografia brasileira e portuguesa das últimas décadas. No Brasil, Laura de Mello e Souza e Fernanda Bicalho situam Boxer no debate dos Impérios modernos (Souza, 2006: 27-77; Bicalho, 2009: 91-105). Em Portugal, na introdução da nova edição de $O$ império marítimo português, 1415-1825, Diogo Ramada Curto faz um balanço da obra de Boxer (Curto, 2011: I- XVI). 
À guisa de conclusão, convém não esquecer que a história é uma construção intelectual cujo objeto não é o tempo neutro, nem homogêneo, mas um tempo "saturado de agoras", formado por múltiplas temporalidades, em que cabe ao historiador compreen der o movimento, perscrutando as fissuras do tempo, num "encontro secreto marcado entre as gerações precedentes e a nossa" (Benjamin, 1987: 223). Trata-se de um diálogo temporal eivado de contradições e interesses - altos e baixos -, que emanam do engajamento no presente (Hartog, 2013) e da expectativa de futuro (Koselleck, 2006). A obra de Boxer só é compreensível à luz da historicidade da década de 1960 - afinal, compreender a historiografia implica compreender dois passados: o do sujeito-narrador e o dos sujeitos narrados.

Notas

1. Agradeço à professora Laura de Mello e Souza, minha supervisora no pós-doutorado na USP, pelo fecundo diálogo. Também registro a enriquecedora contribuição dos professores Francisco Carlos Palomanes Martinho e Abílio Diniz Silva, e um especial agradecimento ao professor João de Pina Cabral, que gentilmente enviou seu texto, à época ainda inédito, importante contribuição para a construção do presente artigo.

2. As citações relativas a Race relations in the Portuguese Colonial Empire, 1415-1825 serão feitas em português, seguindo a tradução brasileira publicada em 1967.

3. Aprofundo a questão em artigo publicado sob o título "Iberismo e luso-tropicalismo na obra de Gilberto Freyre" (2012). Há significativa bibliografia sobre o tema. Ver: Castelo (1999), Cabaço (2007), Dávila (2011), Iñiguez (1999), João (2002), Léonard (2001), Maxwell (2006), Rampinelli (2004) e Thomaz (2002 e 2007).

4. É importante notar a proximidade de Boxer com os círculos historiográficos portugueses próximos do regime salazarista. Muito saudado nos últimos anos, há quem apresente o historiador inglês como um conservador moderado, apenas pontualmente crítico do regime (Curto, 2011: I-XVI).

5. Autores contemporâneos como Fernanda Olival, João Figuerôa-Rego, Francis Dutra, Ângela Barreto Xavier e Giuseppe Marcocci, entre outros, vêm abordando a questão.

6. As citações relativas a The Portuguese seaborne Empire, 1415-1825 serão feitas em português, seguindo a tradução brasileira publicada em 2002.

7. A Segunda Guerra Mundial(1939-1945) apresentou a questão da superioridade racial como um de seus capítulos ideológicos mais significativos. E preciso lembrar que Charles Boxer participou da guerra como membro do Serviço de Inteligência do Exército Britânico e foi feito prisioneiro dos japoneses, em Hong Kong (Alden, 2001: 249-81). 
ALDEN, Dauril. Charles R. Boxer: an uncommon life: soldier, historian, teacher, collector, traveler. Lisboa/Portugal: Fundação Oriente, 2001.

ALMEIDA, Miguel Vale de. Um mar cor $d a$ terra: "raça", cultura e política de identidade. Oeiras/Portugal: Celta, 2000.

BENJAMIN, Walter. Sobre o conceito de História. In: Magia e técnica, arte e política. São Paulo: Brasiliense, 1987.

BICALHO, Maria Fernanda. Da Colônia ao Império. In: SOUZA, Laura de Mello e; FURTADO, Junia; BICALHO, Maria Fernanda (orgs.). O governo dos povos. São Paulo: Alameda Editorial, 2009.

BOXER, Charles Ralph. Salvador de Sá and the struggle for Brazil and Angola, 1602-1686. London/UK: Athlone Press, 1952; trad. bras. Olivério M. de Oliveira Pinto, Salvador de Sá e a luta pelo Brasil e Angola, 16021686. São Paulo: Companhia Editora Nacional, 1973.

The Dutch in Brazil, 1624-1654. Oxford/UK: Clarendon Press, 1957; trad. bras. Olivério M. de Oliveira Pinto, Os holandeses no Brasil, 1624-1654. São Paulo: Companhia Editora Nacional, 1961a.

. The clash of colour, caste, and creed in the Sixteenth Century. In: Four centuries of Portuguese expansion, 1415-1825: a succinct survey. Johannesburg/South Africa: Witwatersrand University Press, 1961b.

- Race relations in the Portuguese Colonial Empire, 1415-1825. Oxford/UK: Oxford University Press (Clarendon), 1963; trad. bras. Elice Munerato, Relações raciais no Império Colonial Português, 1415-1825. Rio de Janeiro: Edições Tempo Brasileiro, 1967.
Resposta a artigos de Armando Cortesão. Revista de História, v. 28, n. 58, abr.-jun. 1964, p. 405-408. São Paulo: Departamento de História - Faculdade de Filosofia, Letras e Ciências Humanas Universidade de São Paulo - FFLCH-USP.

Portuguese society in the tropics: the Municipal Councils of Goa, Macao, Bahia, and Luanda, 1510-1800. Madison-WI/USA: University of Wisconsin Press, 1965.

The Portuguese seaborne Empire, 1415-1825. London/UK, New York/USA: Hutchinson/Knopf, 1969; trad. bras. Olga de Barros Barreto, $O$ império marítimo português, 1415-1825. São Paulo: Companhia das Letras, 2002.

The Church militant and Iberian expansion, 1440-1770. Baltimore-MD/USA: Johns Hopkins University Press, 1978; trad. bras. Vera Maria Pereira, Igreja militante e a expansão Ibérica, 1440-1770. São Paulo: Companhia das Letras, 2007.

CABAÇO, José Luís de Oliveira. Moçambique: identidades, colonialismo e libertação. 2007. 475f. Tese (Doutoramento em Antropologia Social) - FFLCH-USP, São Paulo.

CABRAL, João de Pina. Charles Boxer and the race equivoque. In: BETHENCOURT, Francisco; PEARCE, Adrian. Racism and ethnic relations in the portuguese-speaking world. Oxford/UK: Oxford University Press, 2012.

CATALOGUE OF AN EXHIBITION AT THE BRITISH MUSEUM. Prince Henry the Navigator and the Portuguese Maritime Enterprise. Sep.-Oct., 1960. London/UK: British Museum, 1960. 166p.

CASTELO, Cláudia. "O modo português de estar no mundo": o luso-tropicalismo e a ideologia colonial portuguesa, 1933-1961. 


\section{Charles Boxer (contra Gilberto Freyre)}

Porto/Portugal: Edições Afrontamento, 1999.

CORTESÃO, Armando. Realidades e desvarios africanos. Discurso proferido na Sociedade de Geografia de Lisboa, quando da sessão de encerramento da Semana do Ultramar em 9 de julho de 1962. Lisboa/ Portugal: Sociedade de Geografia de Lisboa/Agência Geral do Ultramar, 1962.

; MARQUES, Alfredo Pinheiro; MOTA, Avelino Teixeira da. Portugaliae Monumenta Cartographica. v. 1. 1, 1960; reimp. Lisboa/Portugal: Imprensa Nacional/Casa da Moeda, 1987.

CERTEAU, Michel de. A operação historiográfica. In: A escrita da história. Rio de Janeiro: Forense Universitária, 1982.

CURTO, Diogo Ramada. Uma história conservadora do império marítimo português?. In: BOXER, Charles. $O$ império marítimo português, 1415-1825. Lisboa/Portugal: Edições 70, 2011.

DÁVILA, Jerry. Hotel Trópico: o Brasil e os desafios da descolonização africana, 19501980. São Paulo: Paz e Terra, 2011.

FREYRE, Gilberto. Casa-grande $\mathcal{E}$ senzala (1933). Rio de Janeiro: Record, 2002.

-O mundo que o português criou. Rio de Janeiro: José Olympio, 1940.

Um brasileiro em terras portuguesas. Rio de Janeiro: José Olympio, 1953a.

Aventura e rotina: sugestões de uma viagem à procura de constantes portuguesas de caráter e ação. Rio de Janeiro: José Olympio, 1953b.

Integração portuguesa nos trópicos. Lisboa/Portugal: Junta de Investigações do Ultramar, 1958.

O luso e o trópico. Lisboa/Portugal: Comissão Executiva do V Centenário da Morte do Infante D. Henrique, 1961.

\author{
Mais sobre o caso do Major Boxer. \\ In: Revista O Cruzeiro. Rio de Janeiro, 23 \\ jan. 1965.
}

GARCIA, João Carlos. Um castelo de cartas antigas: construir e comemorar o Império. In: COELHO, Teresa Pinto (coord.). Os descobrimentos portugueses no mundo de língua inglesa (1880-1972). Lisboa/Portugal: Edições Colibri, 2005.

GUIMARÃES, Lucia Maria P. Afinidades atlânticas: impasses, quimeras e confluências nas relações luso-brasileiras. Rio de Janeiro: Quartet, 2009.

HARTOG, François. Regimes de historicidade: presentismo e experiência do tempo. Belo Horizonte/MG: Autêntica, 2013.

IÑIGUEZ, Carlos Pinheiro. Sueños paralelos: Gilberto Freyre y el luso-tropicalismo: identidad, cultura y política en Brasil y Portugal. Buenos Aires/Argentina: Grupo Editor Latinoamericano, 1999.

JOÃO, Maria Isabel. Memória e império: comemorações em Portugal (1880-1960). Lisboa/Portugal: Fundação Calouste Gulbenkian, 2002.

KOSELLECK, Reinhart. Futuro passado: contribuição à semântica dos tempos modernos. Rio de Janeiro: Ed. da PUC-Rio, 2006.

LÉONARD, Yves. O ultramar português. In: BETHENCOURT, Francisco; CHAUDHURI, Kirti. História da expansão portuguesa. v. V. Lisboa/Portugal: Círculo do Livro, 1999.

. Immuable et changeant, le luso-
tropicalisme au Portugal. In: Le Portugal et
l'Atlantique. v. XLII. Lisboa/Portugal, Pa-
ris/France: Arquivos do Centro Cultural
Calouste Gulbenkian, 2001.

MAXWELL, Kenneth. O Império derrotado: revolução e democracia em Portugal. São Paulo: Companhia das Letras, 2006. 
McKENDRICK, Neil. Obituary - Sir John Plum. In: The Guardian, London/UK, Monday, 22 oct. 2001.

MELLO, José Antonio Gonsalves de. Diário de Pernambuco. Recife, 12 mai. 1988.

RAMPINELLI, Waldir José. As duas faces da moeda: as contribuições de $\mathcal{F} K$ e Gilberto Freyre ao colonialismo português. Florianópolis/SC: Editora da UFSC, 2004.

RIBEIRO, Margarida Calafate. Uma história de regressos, império, guerra colonial e pós-colonialismo. Porto/Portugal: Edições Afrontamento, 2004.

SCHNEIDER, Alberto Luiz. Iberismo e luso-tropicalismo na obra de Gilberto Freyre. In: Revista História da Historiografia. n. 10. Ouro Preto/MG: Programa de Pós-Graduação em História - UFOP, dez. 2012. p. 75-93.

SOUZA, Laura de Mello e. Enquadramentos. In: O sol e a sombra: política e administração na América portuguesa do século XVIII. São Paulo: Companhia das Letras, 2006.

\author{
Conduzindo Mr. Boxer. In: Ilus- \\ tríssima - Folha de S. Paulo. São Paulo, do- \\ mingo 25 jul. 2010. p. 7.
}

THOMAZ, Omar Ribeiro. Ecos do Atlântico Sul: representações sobre o terceiro Império português. Rio de Janeiro: Editora da UFRJ, 2002.

Tigres de papel: Gilberto Freyre, Portugal e os países africanos de língua oficial portuguesa. In: BASTOS, Cristiana; ALMEIDA, Miguel Vale de; FELDMAN-BIANCO, Bela (orgs.). Trânsitos coloniais: diálogos luso-brasileiros. $2^{\mathrm{a}}$ ed. Campinas/SP: Editora da Unicamp, 2007.

VAINFAS, Ronaldo. Colonização, miscigenação e questão racial: notas sobre equívocos e tabus da historiografia brasileira. In: Revista Tempo. n. 8. Niterói/RJ: UFF, 1999.

XAVIER, Ângela Barreto. 'O lustre do seu sangue': bramanismo e tópicas de Distinção no Contexto Português. In Revista Tempo. n. 30. Niterói/RJ: UFF, 2011.

\footnotetext{
Resumo

O objetivo deste artigo é discutir a emergência da "questão racial" na leitura que Charles Boxer fez do Império Português. O livro Race relations in the Portuguese Colonial Empire, 1415-1825 (1963) é o marco dessa nova perspectiva agregada à obra do historiador britânico. Essa interpretação foi construída contra as ideias de Gilberto Freyre e de intelectuais próximos ao salazarismo, como Armando Cortesão. Interessa ao artigo investigar e mapear as polêmicas entre esses intelectuais - à luz das grandes questões da época, como a descolonização africana -, que contribuíram para alçar a "raça" ao centro do debate político da década de 1960, repercutindo sobre (e alterando) o entendimento do Império Português da Era Moderna.

Palavras-chave: Charles Boxer; raça e racismo no Império Português; historiografia.
} 
Charles Boxer (contra Gilberto Freyre)

\begin{abstract}
The purpose of this article is to discuss the emergency of the "racial issue" in Charles Boxer's perception of the Portuguese Empire. The book Race relations in the Portuguese Colonial Empire, 1415-1825 (1963) opened this new perspective in the work of the British historian. This new insight was set up in disagreement with the ideas of Gilberto Freyre and other scholars connected to Salazar's regime, such as Armando Cortesão. The article intends to investigate and point the controversies among these scholars - taking into account the great issues of the time, such as the African decolonization -, which have contributed to bring the notion of "race" into the center of the 1960's political debate, therefore reverberating in (and changing) the comprehension of the Portuguese Empire in the Modern Age. Keyzords: Charles Boxer; race and racism in Portuguese Empire; historiography.

\section{Résumé}

Le but de cet article est de discuter l'émergence de la "question raciale" dans l'interprétation de l'Empire Portugais faite par Charles Boxer. Le livre Race relations in the Portuguese Colonial Empire, 1415-1825 (1963) marque la naissance de cette nouvelle perspective dans l'oeuvre de l'historien britannique. Cette interprétation a été construite contre les idées de Gilberto Freyre et des intellectuels proches du salazarisme, comme Armando Cortesão. Notre but est de repérer et d'accompagner les polémiques entre ces intellectuels - à la lumière des grandes questions de l'époque, comme la décolonisation africaine -, qui ont contribué pour amener la "race" au centre du débat politique des années 1960, ce qui a eu des reflexes sur (et a changé) la compréhension de l'Empire Portugais à l'Âge Moderne.

Mots-clés: Charles Boxer; race et racisme dans l'Empire Portugais; historiographie.
\end{abstract}

